\title{
Investigation of Organic Dust Detonation in the Presence of Chemically Inert Particles
}

\author{
R. KLEMENS, M. KAPUSCINSKI, M. WOLINSKI, and P. WOLANSKI \\ Instytut Techniki Cieplnej, Politechnika Warszawa, 00-665 Warszawa, Poland
}

M. SICHEL*

Department of Aerospace Engineering, The University of Michigan, Ann Arbor, MI 48109-2118

\begin{abstract}
The results of experimental studies of organic dust detonation in the presence of chemically inert particles are presented. Tests were carried out using a vertical detonation tube, and direct streak pictures showing the flame acceleration and pressure and temperature records were obtained. Flax dust, dispersed in an oxygen atmosphere, was used as the fuel, and two kinds of quartz sand were introduced as nonreacting particles. It was found that addition of inert particles caused a linear decrease of the detonation wave velocity but had no special influence on the transition distance. Calculations using the Gordon McBride Code showed that propagation of the detonation wave in a dust-oxygen mixture requires that the dust particles burnout at a level of about $70 \%$ but addition of inert particles increased the necessary burnout level to over $80 \%$ (with a significant decrease of the detonation wave velocity).
\end{abstract}

\section{INTRODUCTION}

The aim of this work was to investigate the processes of flame self acceleration and transition to detonation in mixtures of organic dust with oxygen, and to investigate the influence of chemically neutral particles (used as a flame inhibiting agent) on these processes.

It is known that fibers of flax and dusts created by processing of various raw materials are very explosive [1-3]. These dusts can cause severe explosions, killing and injuring people, and destroying industrial facilities (e.g., in Zmigrod, Poland, in 1978 or in Harbin, China, in 1987 [4]). Also, in a previous modeling investigation [5] it was found that flax dust had the lowest value of the minimum dust concentration at which flame acceleration with transition to detonation was observed. As flax is a plant of significant importance in the textile industry it was chosen for further experimental studies of detonation processes in organic dust mixtures.

\footnotetext{
* Corresponding author.

Presented at the Twenty-Fifth Symposium (International) on Combustion, Irvine, California, 31 July-5 August 1994.
}

\section{EXPERIMENTAL SETUP AND DUST SAMPLES}

Tests were carried out in a vertical detonation tube, as described in Ref. [6]. The $8.0-\mathrm{cm}$ diameter tube was $4.5 \mathrm{~m}$ long, of circular cross-section, and with a length to diameter ratio of $L / D=57$. Direct streak pictures of the flame propagation and measurements of pressure and particle temperature in the flame front were obtained. Samples of the dust to be tested were dispersed in an atmosphere of $95 \% \mathrm{O}_{2}$ and $5 \% \mathrm{~N}_{2}$ by volume, and ignited using a low-energy ignition source (fuse heads). In this way observation of the flame self-acceleration downward through the tube was possible, without any influence of the ignition source. All experiments were carried out at atmospheric pressure.

Samples for investigation were prepared using flax dust from a mechanical flax processing house. The diameters $d_{p}$ of the dust particles were all less than $0.09 \mathrm{~mm}$. Analysis revealed the following composition of the dust (\% by weight): volatiles -62.9 , ash -24.90 , and moisture -5.80 . The heat of combustion was equal to $21.6 \mathrm{MJ} / \mathrm{kg}$. Two kinds of white quartz sand

Copyright (C) 1994 by The Combustion Institute Published by Elsevier Science Inc. 
were used as inert particles: with diameter ranges of $0.10<d_{p} \leq 0.16 \mathrm{~mm}$ and $0.40<$ $d_{p} \leq 0.60 \mathrm{~mm}$.

\section{EXPERIMENTAL RESULTS AND DISCUSSION}

The experimental studies started with a determination of the limiting dust concentration at which transition to detonation was possible in the laboratory detonation tube. For this purpose the flame front velocity was measured with increasing levels of dust concentration. It was found that a concentration of $c=0.78$ $\mathrm{kg} / \mathrm{m}^{3}$ was the lean limit. For this concentration it was possible to observe an accelerating deflagration as well as transition to detonation. In this case, the flame acceleration, observed from streak photographs, was gradual but did result in transition to detonation, however without a sharp change in the flame velocity during the process. Pressure profiles recorded slightly ahead of the transition point revealed a structure typical for self-accelerating flames, with the combustion front catching up to the leading shock. However, pressure profiles recorded within the detonation front, for this marginal case, showed a rather complicated structure probably caused by regular trans- verse waves propagating behind the leading shock. Analysis of the light emission profile when compared with the pressure traces showed that the flame very closely followed the leading shock.

A typical streak photograph, pressure traces taken at two different transverse locations, light emission profiles and the particle temperature variation are shown in Fig. 1. The data reported below are based on a whole sequence of such streak photographs and property profiles. Fig. 1 presents the case of transition to detonation for a mixture with $c=0.91 \mathrm{~kg} / \mathrm{m}^{3}$ of dust. In that case, as for $c=0.78 \mathrm{~kg} / \mathrm{m}^{3}$, transition to detonation did not involve a sharp change of the flame front velocity. Pressure profiles recorded at two points at the same cross section of the tube showed significant non-uniformities in the detonation front. Such non-uniformities have also been observed by Zhang and Grönig [8] and by Li et al. [9] and suggest the possible presence of a spinning detonation. But these differences also may reflect nonuniformities in the dust-gas mixture. The light emission profile and the temperature of the burning dust particles were almost constant behind the detonation. The temperature reached a value of $2800 \mathrm{~K}$ and then remained almost constant throughout the duration of the measurement.
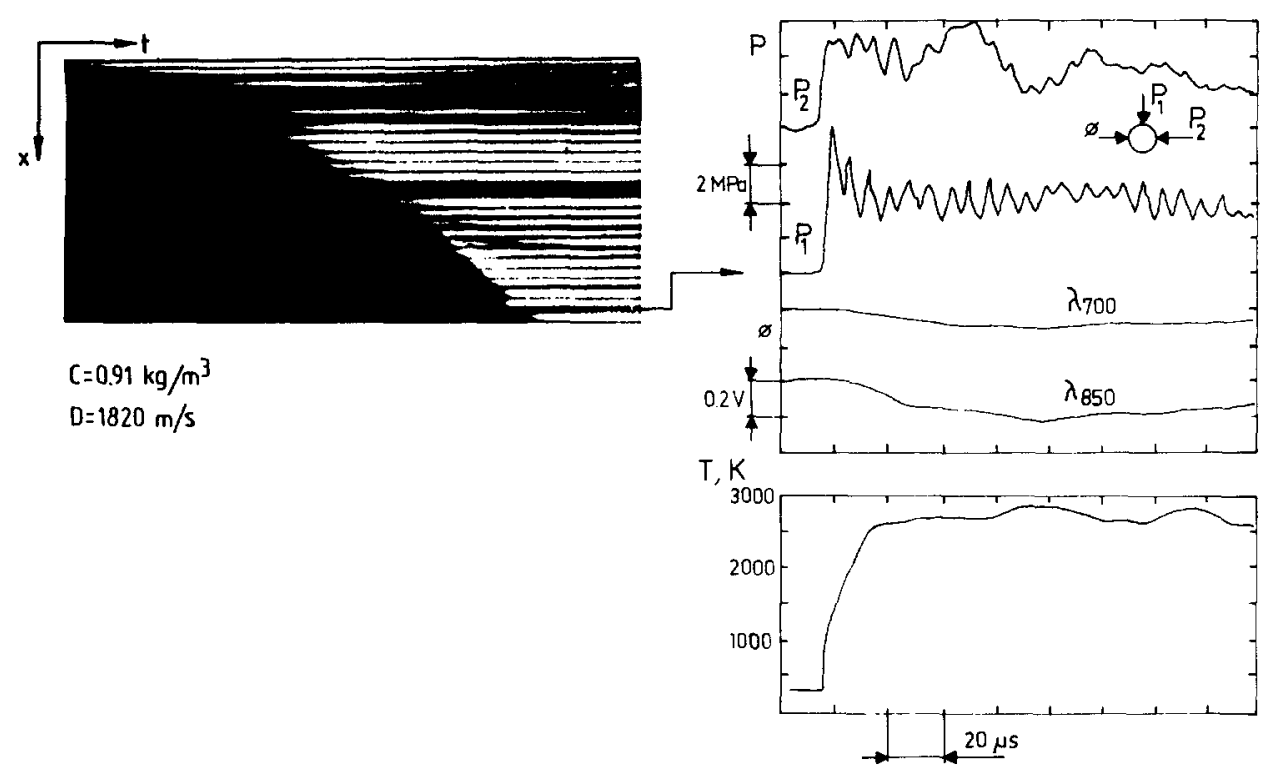

$\mathrm{C}=0.91 \mathrm{~kg} / \mathrm{m}^{3}$

$\mathrm{D}=1820 \mathrm{~m} / \mathrm{s}$ 


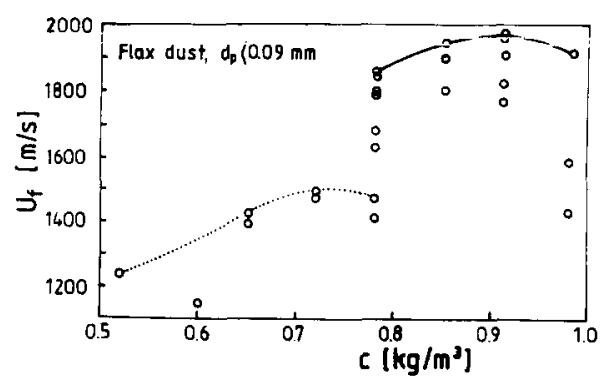

Fig. 2. Influence of the dust concentration on the flame front and detonation velocity.

Figures 2-4 summarize the experimental results and show the influence of the dust concentration on the maximum velocity of the flame front, the maximum pressure in the flame front and the maximum temperature of the burning particles, respectively: In all plots two regimes of flame propagation could be distinguished: acceleration of the flame and detonation. The accelerating flames (for dust concentrations smaller than or equal to $c=0.78$ $\mathrm{kg} / \mathrm{m}^{3}$ ) reached a maximum velocity of about $1500 \mathrm{~m} / \mathrm{s}$ at a concentration $c=0.72 \mathrm{~kg} / \mathrm{m}^{3}$ of dust. The maximum pressure in the combustion front was never greater than $4 \mathrm{MPa}$ (also with $c$ in the range of about $0.72 \mathrm{~kg} / \mathrm{m}^{3}$ ) and the maximum temperature of the burning particles reached $2780 \mathrm{~K}$ for $c=0.72 \mathrm{~kg} / \mathrm{m}^{3}$ of dust.

The maximum parameters of the detonation wave, achieved at a dust concentration of $c=$ $0.91 \mathrm{~kg} / \mathrm{m}^{3}$, were maximum propagation velocity $D=1960 \mathrm{~m} / \mathrm{s}$, maximum pressure about 6.5 $\mathrm{MPa}$, and maximum temperature of burning particles, about $2980 \mathrm{~K}$. This is also the

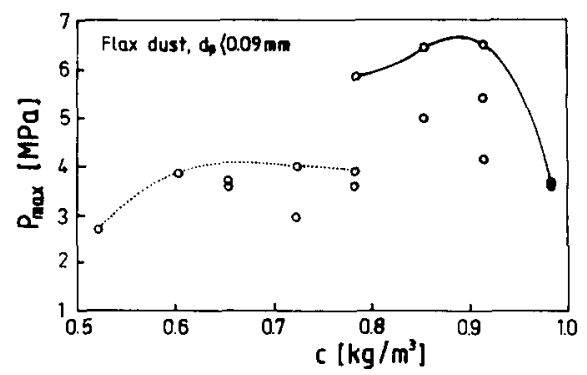

Fig. 3. Influence of the dust concentration on the maximum pressure in the flame and detonation front.

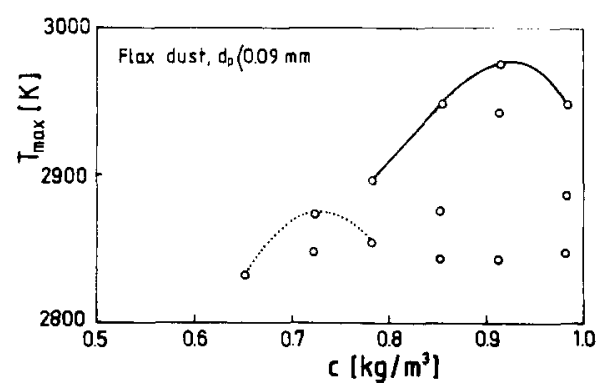

Fig. 4. Influence of dust concentration on the maximum temperature in the flame and detonation front.

case shown in Fig. 1. At this concentration the relative transition distance (distance from the ignition source to the transition point divided by the tube diameter, Fig. 5) achieved a minimum value equal to 43.8 . The concentration equal to $0.91 \mathrm{~kg} / \mathrm{m}^{3}$ can, thus be considered as the optimum concentration for detonation propagation in mixtures of flax dust and oxygen.

After determination of the detonation wave parameters in the undiluted dust-oxygen mixtures the influence of inert particles on detonation propagation was investigated. For this purpose the optimum concentration of dust of $c=0.91 \mathrm{~kg} / \mathrm{m}^{3}$, as determined above, was chosen. The test mixtures were created by the dispersion of combustible dust mixed with suitable amounts of sand.

The data described below is again based on the analysis of a series of experimentally measured streak photographs and property profiles. The main variables considered were the sand loading and the sand particle diameters. Small particles in the size range $0.1<d_{p} \leq$ $0.16 \mathrm{~mm}$, and larger particles in the range

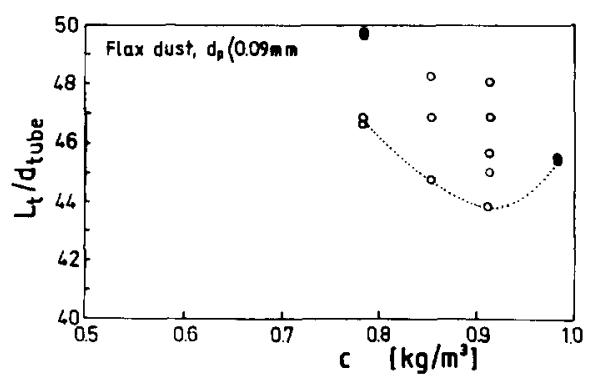

Fig. 5. Influence of the dust concentration on the transition distance. 


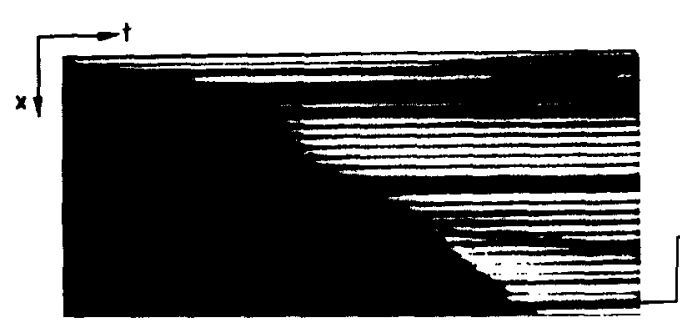

$C=0.91 \mathrm{~kg} / \mathrm{m}^{3} 1+0.73 \mathrm{~kg} / \mathrm{m}^{3}$ sand $0.4-0.6 \mathrm{mml}$

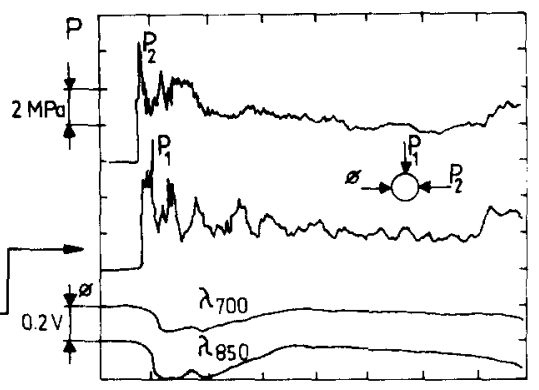

$D=1610 \mathrm{~m} / \mathrm{s}$

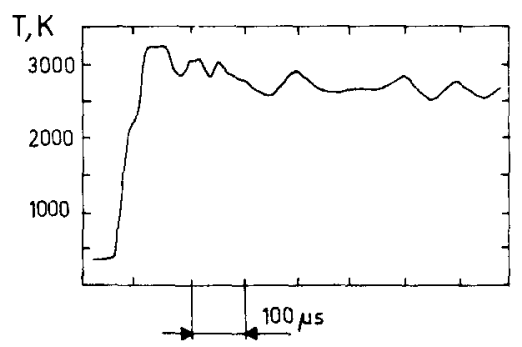

Fig. 6. Flame acceleration and transition to detonation in a mixture containing $0.91 \mathrm{~kg} / \mathrm{m}^{3}$ of flax dust and $0.73 \mathrm{~kg} / \mathrm{m}^{3}$ of quartz sand $\left(0.4<d_{p}<0.6 \mathrm{~mm}\right)$.

$0.4<d_{p} \leq 0.6 \mathrm{~mm}$ were used, and inert particle concentrations up to $0.83 \mathrm{~kg} / \mathrm{m}^{3}$ were investigated.

Figure 6 , with a sand loading of $0.73 \mathrm{~kg} / \mathrm{m}^{3}$, (ca. $45 \%$ inert ballast in the mixture) with particle diameters in the range $0.4<d_{p} \leq$ $0.6 \mathrm{~mm}$ is a typical example of the data observed with inert dust added to the flax dust oxygen mixture. Figure 6 shows the process of transition to detonation. Data for various dust loadings showed that an increase in the fraction of inert matter caused a more intense change of the flame velocity in the transition region as well as a significant decrease of the detonation velocity, while the pressure waves observed in the reaction zone were less intense, apparently due to damping by the inert dust. Increasing the particle diameter from 0.1 $<d_{p} \leq 0.16 \mathrm{~mm}$ to $0.4<d_{p} \leq 0.6 \mathrm{~mm}$ was observed to result in more intense variations in the flame velocity in the transition region for the same dust loading.

The experimental data are summarized in Figs. 7-10, which show the influence of the concentration of both the fine and coarse sand on the detonation velocity, the maximum pressure, the particle temperature in the wave, and the transition distance (as defined previously), respectively. It can be seen in Fig. 7 that the addition of inert particles caused a linear decrease in the detonation velocity. This effect is similar to that observed in gaseous mixtures [7], however it is more intense in the case of dust. Thus, while it was necessary to use about $2 \mathrm{~kg} / \mathrm{m}^{3}$ of sand of diameter $0.4<d_{p} \leq$ $0.6 \mathrm{~mm}$ to quench the gaseous detonation, an inert dust concentration smaller than 0.9 $\mathrm{kg} / \mathrm{m}^{3}$ (of the same sand, in the same detonation tube) was sufficient to quench the dust detonation. It is also noteworthy that for the smaller sand particles the decrease of the detonation velocity was greater for the same sand loading than for the larger particles. This effect is probably caused by the greater interac-

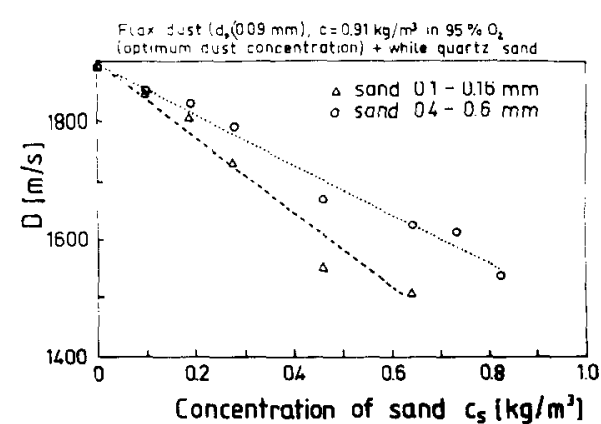

Fig. 7. Influence of sand concentration on the detonation velocity in a mixture of flax dust with $c_{f}=0.91 \mathrm{~kg} / \mathrm{m}^{3}$ in oxygen. 


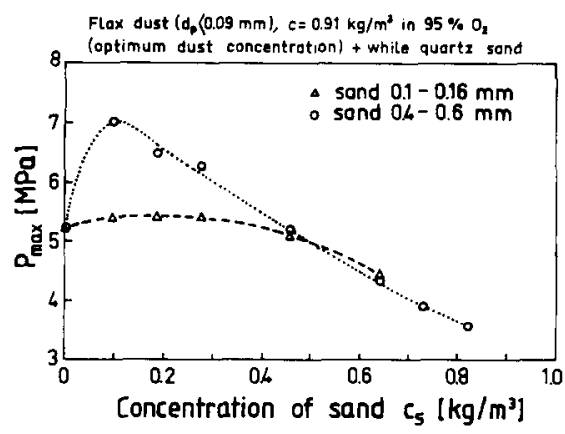

Fig. 8. Influence of sand concentration on the maximum pressure in the detonation front in a mixture of flax dust with $c_{f}=0.91 \mathrm{~kg} / \mathrm{m}^{3}$ in oxygen.

tion of the flow in the reaction zone with the smaller particles which have a greater surface area for the same particle loading so that there are greater heat and momentum losses to the particles).

Figure 8 presents the influence of the sand concentration on the maximum pressure in the detonation wave. It can be seen that even small concentrations of the larger particles caused a significant increase in the maximum pressure $P_{\max }$. For the same range of inert concentration the maximum pressure $P_{\max }$ remained almost constant with the smaller particles. This difference could be caused by the fact that the larger particles are slower to accelerate behind the leading shock and the increased pressure represents the effect of the two phase flow in the reaction zone of the detonation. The decrease in detonation pressure for higher values of sand concentration for both the coarse and fine particles is a

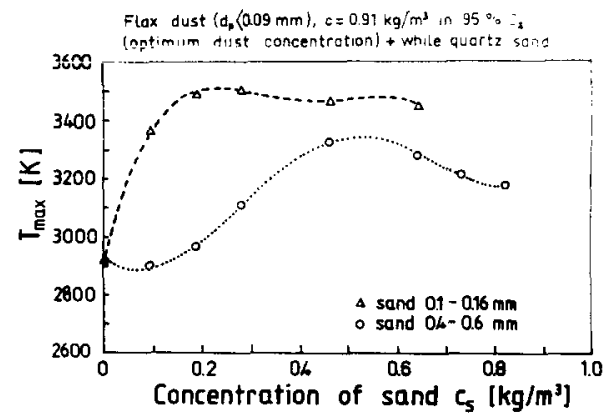

Fig. 9. Influence of sand concentration on the maximum temperature of the burning particles in the detonation front in a mixture of flat dust with $c_{f}=0.91 \mathrm{~kg} / \mathrm{m}^{3}$ in oxygen. consequence of the decrease in detonation velocity with increasing inert dust loading.

Figure 9 indicates that there is a significant increase of the particle temperature in the presence of inert particles (as much as $20 \%$ for the smaller sand particles). A change in the flame color from a yellow-orange dusty flame to an even white flame was also observed during the experiments in mixtures of dust and. inert particles. This effect was probably caused by the introduction of quartz particles with radiative properties different from those of flax dust. The increase in particle temperature may have been confined to only a thin layer on the sand particle surface, and it also should be noted that the method of temperature measurement cannot distinguish between burning and inert particles.

Fig. 10 shows the influence of sand particles on the distance for transition to detonation in flax dust-sand mixtures. It can be seen that the bigger particles had no special influence; however, the smaller particles did cause a slight increase in the transition distance. This lack of effect on transition differs from that observed in gaseous mixtures [7] where addition of inert particles decreased transition distance. However, in the case of dusty mixtures, the addition of inert particles can introduce factors facilitating ignition of dust particles (better dispersion of particles-without agglomerations, increase of small scale turbulence, development of bow shocks around particles) as well as factors inhibiting ignition of dust particles (heat losses in accelerating flames). The final effect appears to be a result of a balance between these factors.

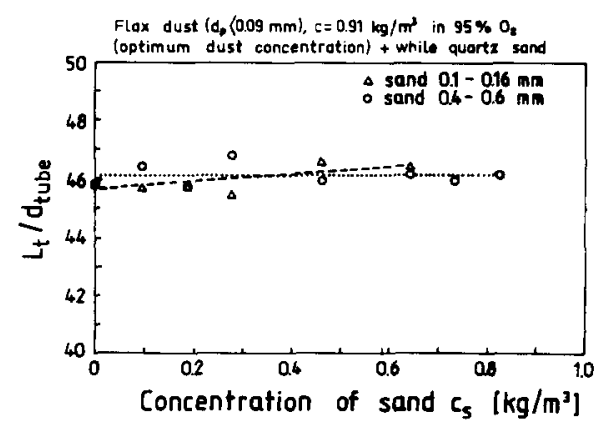

Fig. 10. Influence of sand concentration on the transition distance in a mixture of flax dust with $c_{f}=0.91 \mathrm{~kg} / \mathrm{m}^{3}$ in oxygen. 


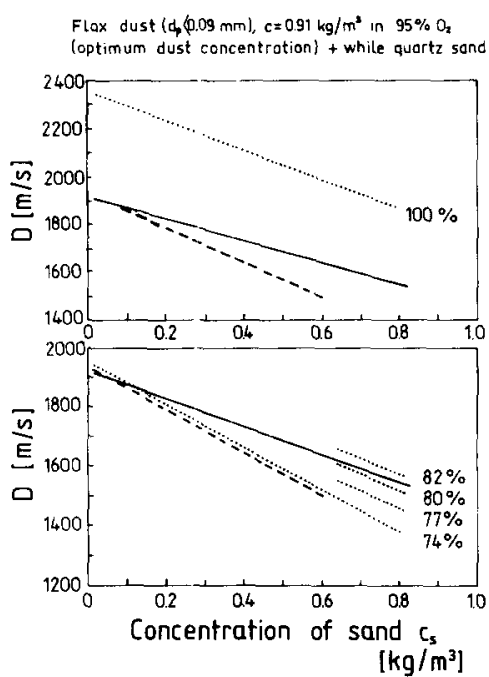

Fig. 11. Comparison between experimental and numerical results on the influence of inert particles on detonation velocity in a suspension of flax dust in oxygen. experiment, sand, $0.4<d_{p}<0.6 \mathrm{~mm}$; $\ldots-\ldots-\ldots$, experiment, sand, $0.1<d_{p}<0.16 \mathrm{~mm}$; $\cdots \cdots \cdots \cdot \ldots$, calculation, $c_{f}=0.93 \mathrm{~kg} / \mathrm{m}^{3}$. Numbers on the plots indicate assumed values of particle burnout percentage.

In Fig. 11 the measured variation of detonation velocity with inert dust concentration for a flax dust concentration $c_{f}=0.92 \mathrm{~kg} / \mathrm{m}^{3}$ is compared with values computed using the Gordon McBride Code [10]. From the upper figure it can be seen that assuming 100\% burnout yields calculated velocities which are $25 \%$ greater than the measured values. The lower figure compares computed values of detonation velocities using a flax dust concentration of $c_{f}=0.91 \mathrm{~kg} / \mathrm{m}^{3}$ but assuming a reduced degree of burnout. It can be seen that the $82 \%$ burnout results are in reasonable agreement with the measured results for the larger sand particles, while the $74 \%$ burnout calculations appear to agree with the larger velocity decrement observed with the smaller sand particles. These calculations suggest that the effect of the inert particles is similar to a reduction in the percentage of the fuel particles which actually react with the oxidizer. However, the Gordon McBride code does not take the complex and important phenomena which occur within the reaction zone of the detonation into account. It is, thus, clear that further more detailed calculations are required to explain the effects of the inert dust.

\section{CONCLUSIONS}

Detonation processes in mixtures of flax dust in oxygen, with the addition of inert particles (quartz sand), were investigated. It was found that in the detonation tube used in the experiments:

1. The lean limit for detonation in flax dust oxygen mixtures was $0.78 \mathrm{~kg} / \mathrm{m}^{3}$.

2. The maximum parameters of the detonation recorded at a concentration equal to $0.91 \mathrm{~kg} / \mathrm{m}^{3}$ were velocity $1960 \mathrm{~m} / \mathrm{s}$, pressure $6.5 \mathrm{MPa}$, temperature of the burning particles $2980 \mathrm{~K}$.

3. Increasing the inert particle concentration caused a linear decrease of the detonation velocity. This effect was more significant for the smaller inert particles.

4. Increasing the inert particle concentration had no special influence on the distance for transition to detonation for the mixtures tested.

5. Numerical calculations suggested that dust particles did not burn out totally in the reaction zone of the detonation wave, and that the addition of inert particles to the mixture increased momentum and heat losses and also appeared to decrease the burnout ratio.

This work was supported by the U.S. Department of Agriculture (Grant No. Fg-Po-370, Project No. P1-Ars-135).

\section{REFERENCES}

1. Radziszewska, J. M., Arch. Combust., 6: 139-149 (1986).

2. Radziszewska, J. M., Arch. Combust., 7: 313-320 (1987).

3. Deng Xufan, Li Hongbin, Kong Dehong, Liao Chiang, Arch. Combust., 9:117-124 (1989).

4. Xu Bowen, Chu Xiaodi, Xu Luwei, Xiang Qiu, Liang Shiming, Cheng Jijian, Wang Zhongeheng, Zhou Yongbin, Tang Yofen, and Xu Lirong, Arch. Combust., 9:305-312, (1989).

5. Kapuscinski, M., and Wolinski, M., XIIth International Symposium on Combustion Processes, BielskoBiaka, Poland, 1991.

6. Dehab, O. M., Kapuscinski, M., Wolanski P., and Wolinski, M., Proceedings of the Fourth International Colloquium on Dust Explosions, Warsaw, Poland, 1991., pp. 371-385. 
7. Wolinski, M., and Wolanski, P., Arch. Combust., 7:353-370, (1987).

8. Zhang, F., Grönig, H., and Borissov, A. A., Eds., Dynamic Structure of Detonation in Gaseous and Dispersed Media, Kluwer Academic, Boston, 1991, pp. 157-213.

9. Li, Y.-C., Harbaugh, A. S., Alexander, C. G., Kauff- man, C. W., and Sichel, M., presented at the Colloquium on Dynamics of Explosions and Reactive Systems, Portugal, August 1993.

10. Gordon, S., and McBride, B. J., NASA. SP-273, 1971. 